\title{
A Water-Filled Body Plethysmograph for the Measurement of Pulmonary Capillary Blood Flow during Changes of Intrathoracic Pressure
}

\author{
Yoshikazu Kawakami, Harold A. Menkes, and Arthur B. DuBois \\ From the Graduate Department of Physiology, School of Medicine, University \\ of Pennsylvania, Philadelphia, Pennsylvania 19104
}

A B S T R A C T A water-filled body plethysmograph was constructed to measure gas exchange in man. As compared to an air-filled plethysmograph, its advantages were greater sensitivity, less thermal drift, and no change from adiabatic to isothermal conditions after a stepwise change of pressure. When five subjects were completely immersed within it and were breathing to the ambient atmosphere, they had a normal heart rate, oxygen consumption, $\mathrm{CO}_{2}$ output, and functional residual capacity. Pulmonary capillary blood flow (Q்) during and after Valsalva and Mueller maneuvers was calculated from measurements of $\mathrm{N}_{2} \mathrm{O}$ uptake. Control measurements of $\dot{Q} c$ were 2.58 liters $/ \mathrm{min}$ per $\mathrm{m}^{2}$ at rest and 3.63 liters/min per $\mathrm{m}^{2}$ after moderate exercise. During the Valsalva maneuver at rest (intrapulmonary pressure: 24, SD 3.0, $\mathrm{mm} \mathrm{Hg}$ ), Q்c decreased from a control of 2.58 , sD 0.43 , liters $/ \mathrm{min}$ per $\mathrm{m}^{2}$ to 1.62 , SD 0.26 , liters $/ \mathrm{min}$ per $\mathrm{m}^{2}$ with a decrease in pulmonary capillary stroke volume from a control of 42.4 , SD 8.8, $\mathrm{ml} / \mathrm{stroke}$ per $\mathrm{m}^{2}$ to 25.2 , sD $5.5, \mathrm{ml} / \mathrm{stroke}$ per $\mathrm{m}^{2}$. After release of the Valsalva, there was an overshoot in Q́c averaging +0.78 , sD 0.41 , liter $/ \mathrm{min}$ per $\mathrm{m}^{2}$ accompanied by a significant increase in heart rate. Similar changes occurred during and after the Valsalva following moderate exercise. During the Mueller maneuver at rest and after exercise, $\dot{Q} c$, heart rate, and central stroke volume did not change significantly.

Dr. Kawakami's present address is First Department of Medicine, School of Medicine, Hokkaido University, Sapporo, Japan.

Dr. Menkes is a Fellow of the American Tuberculosis Association. His present address is Department of Medicine, McGill University, Montreal, Quebec, Canada.

Dr. DuBois is the recipient of a National Institutes of Health Research Career Award.

Received for publication 2 June 1969 and in revised form 2 February 1970.

\section{INTRODUCTION}

Conventional body plethysmographs contain air, whereas the one which is to be described below was filled, instead, with water. There were several advantages to using water instead of air: the sensitivity was greatly increased; the thermal drift was practically eliminated; and finally, a decay of pressure, the adiabatic to isothermal change, did not occur after a sudden change of the pressure inside the plethysmograph.

The water-filled body plethysmograph allowed studies of alveolo-capillary gas exchange before, during, or after a Valsalva or Mueller maneuver. Such studies were of interest because large changes of intrathoracic pressure often occur naturally (e.g. during coughing or straining) and are accompanied by hemodynamic alterations (1-3). However, transient changes of pulmonary capillary blood flow ( $\dot{Q} \mathrm{c})$ have been difficult to measure in man. With the water-filled body plethysmograph, these changes could be determined by measuring $\mathrm{N}_{2} \mathrm{O}$ uptake. In addition, $\mathrm{O}_{2}$ uptake and $\mathrm{CO}_{2}$ output could be measured during Valsalva and Mueller maneuvers.

\section{METHODS}

Description of the water-filled plethysmograph. The waterfilled body plethysmograph was designed and assembled in our department. ${ }^{1}$ Its main parts are shown to scale in Fig. 1. The plethysmograph was basically a vertical cylinder made with rolled steel (thickness $=\frac{3}{16}$ inch), its height $135 \mathrm{em}$, and diameter $90 \mathrm{~cm}$. Its calculated volume was 860 liters. Thc weight of the metal was about $170 \mathrm{~kg}$. A horizontal cylindrical compartment which served as a bag-in-box system (volume

1 The main body of the tank was constructed by $S \& S$ Metal Products Inc., Philadelphia, Pa., and the attachments were made by Mr. Joseph Pili in the Machine Shop, Graduate Department of Physiology, School of Medicine, University of Pennsylvania. 


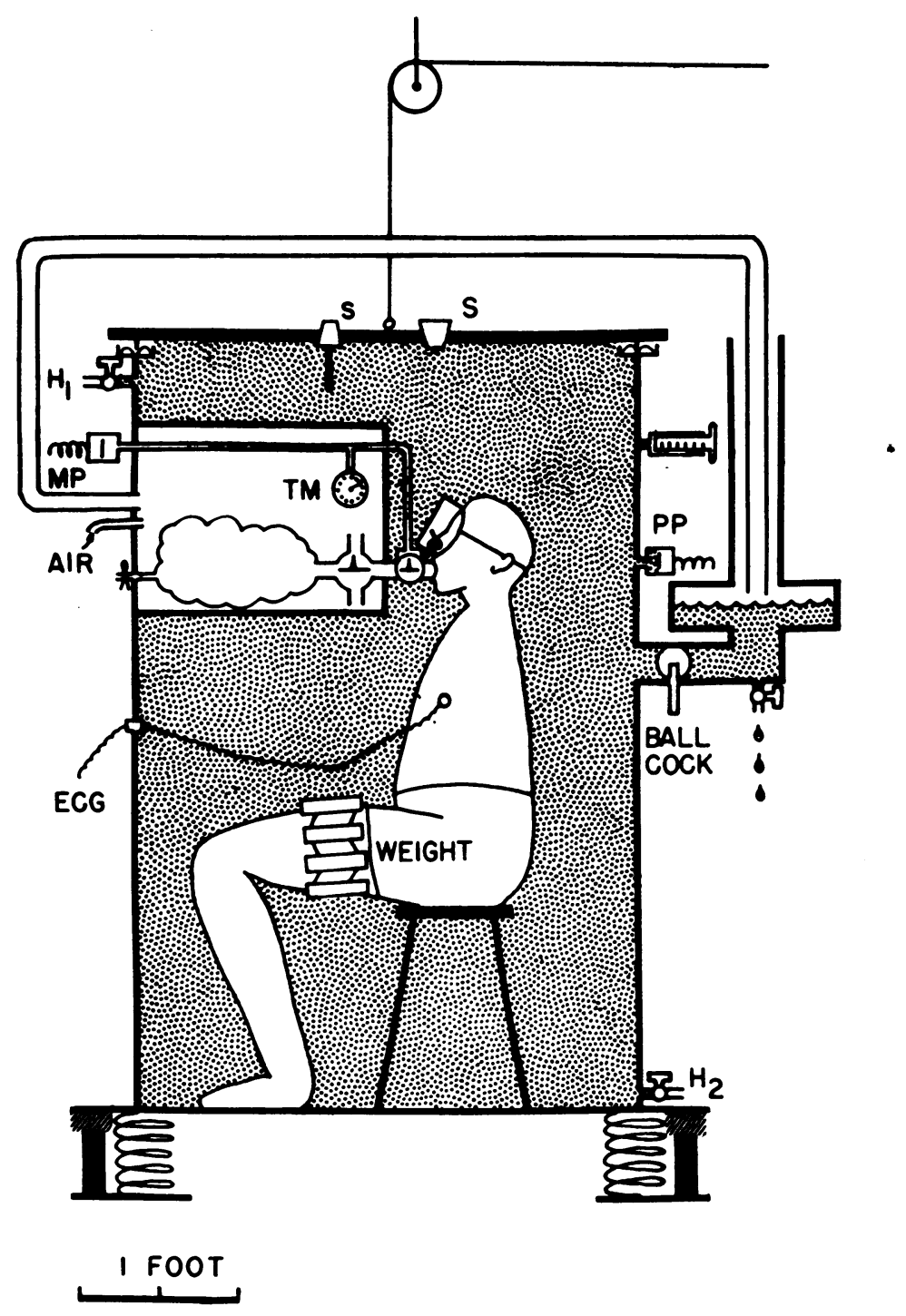

FIGURE 1 Diagram of water-filled body plethysmograph. The plethysmograph sits on springs to absorb vibrations from the floor, and on rubber pads, supported by wood blocks, to damp the slow sidewise oscillations of the plethysmograph. Abbreviations: S: rubber stopper; $\mathrm{H}_{1}$ : Pipe from heater, filter, and circulating pump unit; $\mathrm{H}_{2}$ : Pipe to heater, filter, and circulating pump unit; MP: mouth pressure transducer; TM: Tycos manometer; PP: plethysmograph pressure transducer.

$=13$ liters) was welded into the wall of the plethysmograph. In front and in back it had transparent Plexiglas windows through which the subject could breathe air or gas mixtures from bags.

Around the top edge of the tank a circular steel ring, or flange, was welded. This had a flat upper surface $1 \frac{1}{2}$ inches wide. On this surface a channel was welded, $\frac{5}{8}$ inch deep and $1 \frac{1}{4}$ inches wide. Within this channel, a bead of General Electric Silicone industrial sealant was layed and into this a soaped ring which had been welded under the edge of the lid was pressed. Successive layers of sealant were built up in such a way that the lid's ring then rested in a groove of silicone molded to its own shape. When the channel and groove were subsequently filled with water during an experiment, the fit was airtight and the leak rate very low. The lid was counterbalanced so that it could be raised or lowered easily from either the inside or outside of the tank. Under no circumstances was the lid clamped down on the tank as this would have prevented escape.

A standpipe (internal diameter $12 \mathrm{~cm}$ ) was connected to the wall of the plethysmograph via a ball cock valve and $6 \mathrm{~cm}$ I.D. pipe fitting. The standpipe served to accommodate water 
displaced by the chest during respiration. Its lower part had a segment of wider internal diameter, $30 \mathrm{~cm}$, to lessen the pressure change in the plethysmograph during normal breathing. There was a pressure change of $1.5 \mathrm{~cm} \mathrm{H}_{2} \mathrm{O}$ for 1 liter tidal volume at this wider part.

Water temperature was kept constant at $35^{\circ} \mathrm{C}$ to minimize heat exchange between the subject's body and surrounding water and to keep the metabolic rate close to the basal state (4). Water was circulated through the plethysmograph by a pump (G.E. model 5KH3366 $455 \mathrm{AX}$ ) which was part of a filter-heater system that contained a $500 \mathrm{w}$ immersion heater (No. 6147-B Scientific Apparatus) controlled by a thermistor (Thermistemp Temperature Controller, Yellow Springs Instrument Co., Yellow Springs, Ohio). Plethysmograph pressure was measured with a Statham PR 23-20-300 transducer and mouth pressure with a Statham P $23 \mathrm{Db}$ transducer and these pressures were recorded with an Electronics for Medicine model ER 8 research recorder.

The water-filled body plethysmograph was not completely rigid, but had some flexibility of the lid and baseplate. Its compliance, measured by injecting a known amount of water with a syringe (Fig. 2), was $26 \mathrm{ml} / \mathrm{mm} \mathrm{Hg}$ at $35^{\circ} \mathrm{C}$ and this relation was linear over at least a $200 \mathrm{ml}$ range. Applying Boyle's law relating isothermal gas volumes and pressures, one found that the plethysmograph behaved like a 19 liter isothermal gas-filled plethysmograph at $35^{\circ} \mathrm{C}$ or that its sensitivity was about 32 times greater than that of a 600 liter isothermal air-filled plethysmograph. The $90 \%$ response time, checked by pressing on the lid and then suddenly releasing it, was $0.03 \mathrm{sec}$ with no air in the plethysmograph. Sinusoidal displacement of air to and from a bag containing $1.5,8$, or 30 liters of air underwater in the plethysmograph yielded a dynamic frequency response characteristic which was flat up to $6 \mathrm{cps}$ and peaked at 9-11 cps.

Vibrations were occasionally transmitted from the floor of the building to the water in the tank, whose lid and bottom had some flexibility. Therefore, the tank was shock mounted on four large, coiled springs which supported its base off the floor. This reduced the vibrations to the level seen in Fig. 2, but introduced some swaying at about $1 \mathrm{cps}$. This sidewise sway was limited by wooden blocks and 1 inch rubber pads placed between the floor and the tank. Some vibrations then appeared in the record, giving a noise level equal to about $0.2 \mathrm{ml}$ of volume calibration. The floor of the room was too flexible, and a basement floor would have been preferable.

Experimental procedure. Experiments were performed on five well trained normal subjects. First the subjects, in an almost basal state, had metabolic studies done before they entered the plethysmograph. $\mathrm{O}_{2}$ consumption $\left(\dot{\mathrm{V}}_{2}\right)$ was measured by a closed circuit method. The subject breathed $100 \% \mathrm{O}_{2}$ for $7 \mathrm{~min}$ from a 6 liter spirometer which contained a $\mathrm{CO}_{2}$ absorber. $\mathrm{CO}_{2}$ output $\left(\dot{\mathrm{V}} \mathrm{CO}_{2}\right)$ was studied by collecting expired gas in the spirometer and analyzing $\mathrm{CO}_{2}$ concentration with an infrared analyzer (Liston Becker model 16). This procedure was repeated three times and an average value taken. Frequency of breathing, tidal volume, and minute volume were calculated from records obtained during the $\dot{\mathrm{V}}_{2}$ measurements. Functional residual capacity was measured using an air-filled plethysmograph (5).

After completing the metabolic studies in air, the subject climbed into the plethysmograph and breathed through a mouthpiece attached to the breathing compartment (Fig. 1). The compartment was pressurized by a supply of humidified compressed air. Its pressure was regulated by a tube which extended from the compartment to the standpipe and acted like an underwater blow-off valve at the wider portion of the standpipe. After the lid had been lowered onto the plethys-

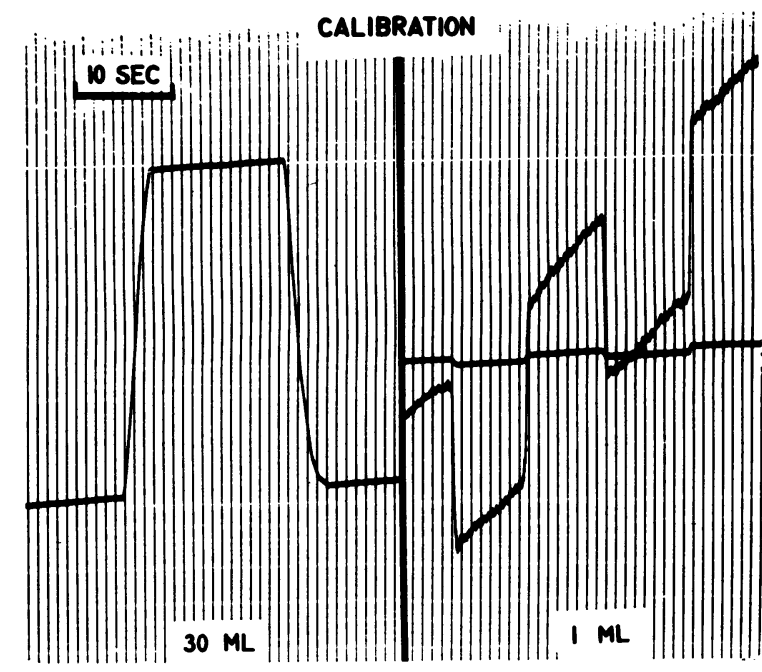

Figure 2 Sensitivity of the plethysmograph pressure to changes in plethysomograph volume. Left: calibration with $30 \mathrm{ml}$ of water. Right: amplified signal, and calibration with $1 \mathrm{ml}$ of water. The drift is caused by a slow inward leak rate $(4 \mathrm{ml} / \mathrm{min})$.

mograph, the water level in the standpipe was reduced gradually until ambient atmospheric pressure inside the plethysmograph was at the level of the subject's shoulders and $9 \mathrm{~cm}$ below the mouthpiece. He could then breathe room air comfortably. The air supply to the breathing compartment was continued throughout the experiment

Each new subject was trained in an escape procedure at the beginning of the experiments. This procedure allowed him to get out of the plethysmograph at any time without any assistance. If he wished to escape, the subject first released the negative pressure under the lid by pushing up a rubber stopper and then raised the lid so that he could stand with his head out of the water. During the experiments, escape was necessary in two cases when the operator forgot to open the breathing tube or standpipe valve after a period of breath holding; the subject emerged without difficulty.

When the subject felt comfortable in the plethysmograph, usually after about $20 \mathrm{~min}$, the metabolic studies were repeated under water. Pulmonary capillary blood flow was measured by the method of Lee and DuBois (6). For a control the subject took a breath of air, then expired to functional residual capacity (FRC), delivering the first alveolar sample. He then held his breath and the plethysmograph was sealed. During the next $10 \mathrm{sec}$ the plethysmograph pressure, mouth pressure (equal to alveolar pressure with glottis open), and EKG were recorded. Changes in plethysmograph and mouth pressure reflected lung volume changes attributable to net gas exchange between the alveoli and the blood. The $\mathrm{R}$ effect $\left(\dot{\mathrm{V}}_{2}-\dot{\mathrm{V}} \mathrm{CO}_{2}\right)$ was seen during breathholding on air (Fig. $3 \mathrm{~A}$ ).

When the subject had completed his breathholding, he expired to residual volume to deliver a second alveolar sample before breathing room air. After a short rest, he inspired a gas mixture of $80 \% \quad \mathrm{~N}_{2} \mathrm{O}+20 \% \quad \mathrm{O}_{2}$ and performed the same maneuvers as those with air (Fig. $3 \mathrm{~B}$ ). $\mathrm{N}_{2} \mathrm{O}$ was analyzed from the mouthpiece by an infrared $\mathrm{N}_{2} \mathrm{O}$ analyzer (Liston Becker model 16). During subsequent breath-holding procedures Valsalva or Mueller maneuvers were done. At the start of breath holding, the subject strained to a predeter- 
TABLE IA

Control and Valsalva

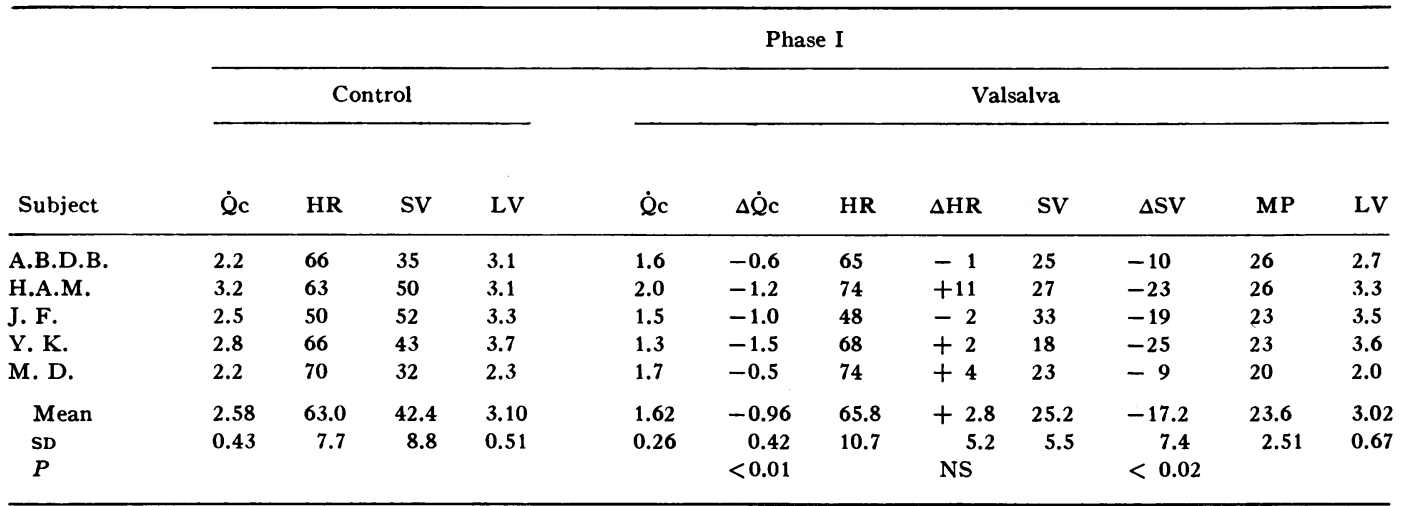

I,V: lung volume (liters), @́c: pulmonary capillary blood flow (liters/min per $\mathrm{m}^{2}$ ), HR: heart rate (beats/min), SV: stroke volume $\left(\mathrm{ml} /\right.$ stroke per $\left.\mathrm{m}^{2}\right), \mathrm{MP}$ : mouth pressure $(\mathrm{mm} \mathrm{Hg})$, and $\Delta \dot{\mathrm{Q}} \mathrm{c}, \Delta \mathrm{HR}, \Delta \mathrm{SV}$ : changes in $\dot{\mathrm{Q}} \mathrm{c}, \mathrm{HR}, \mathrm{SV}$ respectively. Each value represents the mean of two determinations. Statistical analysis was done by comparing paired values obtained on each subject.

NS $=P>0.05$.

The 10 sec breath holding period was divided into two 5 -sec phases (phases I and II). The first four columns under phase I include control values (no Valsalva). The other columns under phase I include values obtained during the Valsalva and are compared to the controls. The first three columns under phase II include control values. The other columns under phase II include values obtained following the release of the Valsalva. This release period was divided into phases II A and II B and the values compared to the controls.

TABLE I B

Control and

\begin{tabular}{|c|c|c|c|c|c|c|c|c|c|c|c|c|}
\hline \multirow[b]{3}{*}{ Subject } & \multicolumn{11}{|c|}{ Phase I } & \\
\hline & \multicolumn{4}{|c|}{ Control } & \multicolumn{8}{|c|}{ Mueller } \\
\hline & $\dot{Q} \mathbf{c}$ & HR & SV & LV & $\dot{\mathrm{Q}} \mathrm{c}$ & $\Delta \dot{\mathrm{Q}} \mathrm{c}$ & HR & $\Delta \mathrm{HR}$ & SV & $\Delta \mathrm{SV}$ & MP & LV \\
\hline A. B. D. B. & 2.3 & 66 & 35 & 3.1 & 3.2 & +0.9 & 69 & +3 & 46 & +11 & -36 & 2.2 \\
\hline H. A. M. & 3.2 & 63 & 50 & 3.1 & 3.1 & -0.1 & 66 & +3 & 47 & -3 & -29 & 3.1 \\
\hline J. F. & 2.5 & 50 & 52 & 3.3 & 2.0 & -0.5 & 47 & -3 & 43 & -9 & -28 & 3.3 \\
\hline Y. K. & 2.8 & 66 & 43 & 3.7 & 2.4 & -0.4 & 67 & +2 & 35 & -8 & -22 & 3.7 \\
\hline Mean & 2.70 & 61.3 & 45.0 & 3.30 & 2.68 & -0.03 & 62.3 & +1.3 & 42.8 & -2.3 & -28.8 & 3.08 \\
\hline SD & 0.39 & 7.6 & 7.7 & 0.28 & 0.57 & 0.64 & 10.2 & 2.9 & 5.4 & 9.2 & . 5.7 & 0.63 \\
\hline$P$ & & & & & & NS & & NS & & NS & & \\
\hline
\end{tabular}

$\mathrm{NS}=P>0.05$

For abbreviations see Table I.

mined mouth pressure by watching a Tycos anaeroid blood pressure manometer, kept his mouth pressure relatively constant for $5 \mathrm{sec}$, and then relaxed suddenly and held his breath for another $5 \mathrm{sec}$ (Fig. $4 \mathrm{~A}$ and B). All procedures were repeated at least twice in random order.

After these experiments had been completed at rest, they were done after exercise. The exercise consisted of cyclic leg motion at a rate of approximately $1 \mathrm{cps}$ for $2 \mathrm{~min}$ with a 15 lb. weighted belt lying across the subject's knees. A few seconds after the cessation of each 2 min of exercise a breathholding maneuver was performed.

Approximate $\mathrm{O}_{2}$ uptake was measured independently from $\mathrm{CO}_{2}$ output in one subject (H.A.M) by having him hold his breath after inspiring a gas mixture containing $7.5 \% \mathrm{CO}_{2}$, $21 \% \mathrm{O}_{2}$, and the remainder $\mathrm{N}_{2}$. When alveolar samples at the beginning and end of breath holding had equal $\mathrm{CO}_{2}$ content it was assumed that gas uptake was equal to the $\mathrm{O}_{2}$ uptake. By subtracting a control slope obtained after he inspired air, $\mathrm{V} \mathrm{CO}_{2}$ was calculated.

Calculations. The rate of gas absorption was calculated with the following formula:

$$
\Delta \mathrm{V}_{\mathrm{L}}^{\mathrm{GA}}=K\left(\Delta \mathrm{P}_{\mathrm{P}}-\frac{\Delta \mathrm{P}_{\mathrm{P}}^{\mathrm{v}}}{\Delta \mathrm{P}_{\mathrm{L}}^{\mathrm{v}}} \cdot \Delta \mathrm{P}_{\mathrm{L}}\right)
$$

$\Delta \mathrm{V}_{\mathrm{L}} \mathrm{GA}^{\mathrm{A}}$ : change in volume of lung gas because of gas

$K$ : absorption or evolution

calibration factor for converting plethys$\Delta \mathrm{P}_{\mathrm{P}}$ : observed change in plethysmograph pressure 


\begin{tabular}{|c|c|c|c|c|c|c|c|c|c|c|c|c|c|c|}
\hline \multicolumn{15}{|c|}{ Phase II } \\
\hline \multicolumn{3}{|c|}{ Control } & \multicolumn{12}{|c|}{ After Valsalva } \\
\hline \multirow[b]{2}{*}{$\dot{Q}_{c}$} & \multirow[b]{2}{*}{ HR } & \multirow[b]{2}{*}{ sv } & \multicolumn{6}{|c|}{ Phase II A } & \multicolumn{6}{|c|}{ Phase II B } \\
\hline & & & $\dot{\mathrm{Q}}_{\mathrm{c}}$ & $\Delta \dot{\mathbf{Q}} \mathrm{c}$ & HR & $\Delta \mathrm{HR}$ & $\dot{s v}$ & $\Delta \mathrm{SV}$ & $\dot{Q}_{c}$ & $\Delta \dot{\mathrm{Q}} \mathrm{c}$ & HR & $\Delta \mathrm{HR}$ & sv & $\Delta \mathrm{SV}$ \\
\hline 1.9 & 64 & 29 & 3.2 & +1.3 & 73 & +9 & 43 & +14 & 2.3 & +0.4 & 68 & +4 & 34 & +5 \\
\hline 3.1 & 63 & 48 & 4.2 & +1.1 & 94 & +31 & 45 & -3 & 3.4 & +0.3 & 67 & +4 & 50 & +2 \\
\hline 1.9 & 47 & 41 & 2.6 & +0.7 & 5.3 & +6 & 50 & +9 & 2.0 & +0.1 & 51 & +4 & 39 & -2 \\
\hline 3.0 & 64 & 46 & 3.5 & +0.5 & 78 & +14 & 45 & -1 & 3.1 & +0.1 & 71 & +7 & 44 & -2 \\
\hline 2.0 & 70 & 28 & 2.3 & +0.3 & 86 & +16 & 27 & -1 & 2.4 & +0.4 & 74 & +4 & 42 & +4 \\
\hline \multirow{3}{*}{0.61} & 61.6 & 38.4 & 3.16 & +0.78 & 76.8 & +15.2 & 42.0 & +3.6 & 2.64 & +0.26 & 66.2 & +4.6 & 39.8 & +1.4 \\
\hline & 8.6 & 9.4 & 0.75 & 0.41 & 15.5 & 9.7 & 8.8 & 7.8 & 0.59 & 0.15 & 8.9 & 1.3 & 7.4 & 3.4 \\
\hline & & & & $<0.01$ & & $<0.025$ & & NS & & $<0.02$ & & $<0.005$ & & NS \\
\hline
\end{tabular}

Mueller at Rest

\begin{tabular}{|c|c|c|c|c|c|c|c|c|c|c|c|c|c|c|}
\hline \multicolumn{15}{|c|}{ Phase II } \\
\hline \multicolumn{3}{|c|}{ Control } & \multicolumn{12}{|c|}{ After Mueller } \\
\hline \multirow[b]{2}{*}{$\dot{Q} \mathrm{c}$} & \multirow[b]{2}{*}{ HR } & \multirow[b]{2}{*}{ SV } & \multicolumn{6}{|c|}{ Phase II A } & \multicolumn{6}{|c|}{ Phase II B } \\
\hline & & & $\dot{\mathrm{Q} c}$ & $\Delta \dot{\mathbf{Q}} \mathrm{c}$ & HR & $\Delta \mathrm{HR}$ & sV & $\Delta \mathrm{SV}$ & $\dot{\mathrm{Q}} \mathrm{c}$ & $\Delta \dot{Q} \mathrm{c}$ & HR & $\Delta \mathrm{HR}$ & SV & $\Delta \mathrm{SV}$ \\
\hline 1.9 & 64 & 29 & 2.4 & +0.5 & 64 & +1 & 37 & +8 & 2.8 & +0.9 & 66 & +2 & 44 & +15 \\
\hline 3.1 & 63 & 48 & 3.1 & 0.0 & 66 & +3 & 47 & -1 & 3.4 & +0.3 & 71 & +8 & 47 & -1 \\
\hline 1.9 & 47 & 41 & 1.8 & -0.1 & 45 & -2 & 41 & 0 & 2.1 & +0.2 & 46 & -2 & 46 & +5 \\
\hline 3.1 & 64 & 46 & 2.3 & -0.7 & 65 & +1 & 35 & -11 & 2.5 & -0.5 & 66 & +2 & 39 & -7 \\
\hline 2.48 & 59.5 & 41.0 & 2.40 & -0.08 & 60.0 & +0.8 & 40.0 & -1.0 & 2.70 & +0.23 & 62.3 & +2.5 & 44.0 & +3.0 \\
\hline \multirow[t]{2}{*}{0.67} & 8.3 & 8.5 & 0.54 & 0.49 & 10.0 & 2.1 & 5.3 & 7.8 & 0.55 & 0.57 & 11.1 & 4.1 & 3.6 & 9.4 \\
\hline & & & & NS & & NS & & NS & & NS & & NS & & NS \\
\hline
\end{tabular}

$\Delta \mathrm{P}_{\mathrm{L}}$ :

observed change in mouth pressure (lung pressure)

$\Delta \mathrm{P}_{\mathrm{P}} \mathrm{v} / \Delta \mathrm{P}_{\mathrm{L}} \mathrm{v}$ : ratio of change in plethysmograph pressure to that of mouth pressure evoked by compression or decompression of intrathoracic gas. This ratio and Boyle's Law were used to calculate lung volume (5).

An explanation of the derivation of this equation is found in the Appendix.

Pulmonary capillary bloodflow ( $\dot{\mathrm{Q}} \mathrm{c}$ ) was calculated by Fick's equation:

$$
\dot{\mathrm{Q}} \mathrm{c}=\frac{\dot{\mathrm{V}}_{2} \mathrm{O} \times 1.09 \times(\mathrm{B}-47)}{470 \times \mathrm{P}_{\mathrm{A}_{2} \mathrm{O}}}(\text { liters } / \mathrm{min})
$$

$\dot{\mathrm{V}}_{2} \mathrm{O}$ : apparent uptake of $\mathrm{N}_{2} \mathrm{O}(\mathrm{ml} / \mathrm{min})\left(\mathrm{N}_{2} \mathrm{O}\right.$ recordcontrol)

B-47: barometric pressure in $\mathrm{mm} \mathrm{Hg}$ minus partial pressure of water vapor at $37^{\circ} \mathrm{C}$

470: Ostwald solubility coefficient of $\mathrm{N}_{2} \mathrm{O}$ in $37^{\circ} \mathrm{C}$ blood (ml BTPD/liter of blood per atm) (7)

1.09: a combination of three correction factors. (a) For $\mathrm{N}_{2}$ which diffuses from the blood into the alveoli $(+3 \%)(8)$. (b) For $\mathrm{N}_{2} \mathrm{O}$ which leaves pulmonary parenchyma into the alveoli or blood $(+8 \%)(8)$. (c) For $\mathrm{CO}_{2}$ which leaves the alveoli because it is concentrated when $\mathrm{N}_{2} \mathrm{O}$ is preferentially absorbed by the blood $(-2 \%)$. Assuming a lung volume of $3000 \mathrm{ml}$, a $\mathrm{PA}_{\mathrm{CO}_{2}}$ of $40 \mathrm{~mm} \mathrm{Hg}$, a $\mathrm{CO}_{2}$ 
TABLE II A

Control and Valsalva

\begin{tabular}{|c|c|c|c|c|c|c|c|c|c|c|c|c|}
\hline \multirow[b]{3}{*}{ Subject } & \multicolumn{12}{|c|}{ Phase I } \\
\hline & \multicolumn{4}{|c|}{ Control } & \multicolumn{8}{|c|}{ Valsalva } \\
\hline & $\dot{Q} \mathbf{c}$ & HR & sv & LV & $\dot{Q} c$ & $\Delta \dot{\mathrm{Q}} \mathrm{c}$ & HR & $\Delta \mathrm{HR}$ & SV & $\Delta \mathrm{SV}$ & MP & LV \\
\hline A. B. D. B. & 3.4 & 84 & 40 & 3.0 & 2.5 & -0.9 & 90 & +6 & 28 & -12 & 25 & 2.7 \\
\hline H. A. M. & 4.0 & 81 & 49 & 2.8 & 2.6 & -1.4 & 75 & -6 & 36 & -13 & 28 & 3.0 \\
\hline J. F. & 3.5 & 80 & 45 & 2.3 & 2.7 & -0.8 & 73 & -7 & 38 & -5 & 16 & 2.7 \\
\hline Y. K. & 3.6 & 80 & 45 & 2.7 & 2.4 & -1.2 & 93 & +13 & 25 & -20 & 15 & 2.6 \\
\hline Mean & 3.63 & 81.3 & 44.8 & 2.70 & 2.55 & -1.07 & 82.8 & +1.5 & 31.8 & -12.5 & 21.0 & 2.75 \\
\hline SD & 0.26 & 1.9 & 3.7 & 0.29 & 0.13 & 0.28 & 10.2 & 9.7 & 6.2 & 6.14 & 6.5 & 0.17 \\
\hline$P$ & & & & & & 0.005 & & NS & & 0.05 & & \\
\hline
\end{tabular}

TABLE II B

After Exercise,

\begin{tabular}{|c|c|c|c|c|c|c|c|c|c|c|c|c|}
\hline \multirow[b]{3}{*}{ Subject } & \multicolumn{12}{|c|}{ Phase I } \\
\hline & \multicolumn{4}{|c|}{ Control } & \multicolumn{8}{|c|}{ Mueller } \\
\hline & $\dot{Q} c$ & HR & sv & LV & $\dot{Q} c$ & $\Delta \dot{\mathrm{Q}} \mathrm{c}$ & HR & $\Delta \mathrm{HR}$ & SV & $\Delta \mathrm{SV}$ & MP & LV \\
\hline A. B. D. B. & 3.4 & 84 & 40 & 3.0 & 3.8 & +0.4 & 90 & +6 & 43 & +3 & -34 & 2.1 \\
\hline H. A. M. & 4.0 & 81 & 49 & 2.8 & 4.3 & +0.3 & 73 & -8 & 58 & +9 & -29 & 2.8 \\
\hline J. F. & 3.5 & 80 & 45 & 2.3 & 3.5 & 0 & 72 & -8 & 49 & +4 & -26 & 2.8 \\
\hline Y. K. & 3.5 & 80 & 45 & 2.7 & 4.7 & +1.2 & 104 & +24 & 45 & +0 & -30 & 2.7 \\
\hline Mean & 3.6 & 81.3 & 44.8 & 2.70 & 4.08 & +0.48 & 84.8 & +3.5 & 48.8 & +4.0 & -29.8 & 2.60 \\
\hline SD & 0.27 & 1.9 & 3.7 & 0.29 & 0.53 & 0.51 & 15.3 & 15.2 & 6.7 & 3.7 & 3.3 & 0.34 \\
\hline$P$ & & & & & & NS & & NS & & NS & & \\
\hline
\end{tabular}

dissociation slope for lung tissue, and pulmonary capillary blood $(100 \mathrm{cc})$ of $2.2 \mathrm{cc} \mathrm{STPD} / \mathrm{mm} \mathrm{Hg}$ (9) a correction of $(-2 \%)$ is needed because $\mathrm{CO}_{2}$ leaves the alveolar gas.

$\mathrm{P}_{\mathrm{A}_{2} \mathrm{O}}$ : mean partial pressure of alveolar $\mathrm{N}_{2} \mathrm{O}$, including a correction for the partial pressure change in the lung during Valsalva and Mueller maneuvers. $\mathrm{PA}_{\mathrm{A}_{2} \mathrm{O}}$ was assumed to decrease linearly with time during the relatively short period of breathholding.

\section{RESULTS}

The effects of total immersion on breathing frequency, tidal volume, minute volume, oxygen consumption, $\mathrm{CO}_{2}$ output, respiratory exchange ratio, functional residual capacity, and heart rate are summarized in Fig. 5. The frequency of respiration decreased in all subjects after immersion (mean decrease $16 \%$, $P<0.025$ ). Tidal volume, minute volume, oxygen consumption, $\mathrm{CO}_{2}$ output, and heart rate did not change significantly. All subjects had a decrease in respiratory exchange ratio (mean decrease $10 \%$, $P<0.05)$.

The lung volumes at which the subjects held their breath in water (mean 3.1, SD 0.5, liters) were not significantly different from their FRC values as measured in the air-filled body plethysmograph (mean 3.6, SD 0.6, liters). However, during immersion the subjects held their breath at lower lung volumes after exercise than at rest (mean 2.6, sD 0.3 , liters, $0.025<P<0.05$ ).

When analyzing the records obtained during breathholding, we divided them into two 5 -sec phases (Table I A). Control values (no Valsalva or Mueller) are shown in the first four columns under "phase I" and the first three columns under "phase II". Values obtained during the Valsalva are shown in the other columns under phase I and values obtained after the release of the Valsalva are shown under phase II. These are compared to control values. Phase II of the Valsalva (the release period) was divided into two parts (II A, early and II B, late). Table I B shows values obtained 
after Exercise

\begin{tabular}{|c|c|c|c|c|c|c|c|c|c|c|c|c|c|c|}
\hline \multicolumn{15}{|c|}{ Phase II } \\
\hline \multicolumn{3}{|c|}{ Control } & \multicolumn{12}{|c|}{ After Valsalva } \\
\hline \multirow[b]{2}{*}{$\dot{\mathrm{Q}} \mathrm{c}$} & \multirow[b]{2}{*}{ HR } & \multirow[b]{2}{*}{ sv } & \multicolumn{6}{|c|}{ Phase II A } & \multicolumn{6}{|c|}{ Phase II B } \\
\hline & & & $\dot{\mathrm{Q} c}$ & $\Delta \dot{Q} \mathrm{c}$ & HR & $\Delta \mathrm{HR}$ & sv & $\Delta \mathrm{SV}$ & $\dot{Q} c$ & $\Delta \dot{\mathrm{Q}} \mathrm{c}$ & HR & $\Delta \mathrm{HR}$ & sv & $\Delta \mathrm{SV}$ \\
\hline 3.4 & 82 & 41 & 3.8 & +0.4 & 92 & +10 & 42 & +1 & & & & & & \\
\hline 3.3 & 68 & 49 & 5.1 & +1.8 & 95 & +27 & 53 & +4 & 3.5 & +0.2 & 62 & -6 & 56 & +7 \\
\hline 3.0 & 66 & 45 & 3.4 & +0.4 & 67 & +1 & 51 & +6 & 2.8 & -0.2 & 56 & -10 & 50 & +5 \\
\hline 3.2 & 74 & 43 & 4.6 & +1.4 & 95 & +21 & 49 & +6 & 3.6 & +0.4 & 72 & -2 & 51 & +8 \\
\hline 3.23 & 72.5 & 44.5 & 4.22 & +1.0 & 87.3 & 14.8 & 48.8 & +4.3 & 3.30 & +0.13 & 63.3 & -6.0 & 52.3 & +6.7 \\
\hline \multirow[t]{2}{*}{0.17} & 7.18 & 3.4 & 0.76 & 0.71 & 13.6 & 11.6 & 4.8 & 2.36 & 0.44 & 0.4 & 8.1 & 4.0 & 3.2 & 1.5 \\
\hline & & & & $<0.05$ & & NS & & $<0.05$ & & NS & & NS & & $<0.05$ \\
\hline
\end{tabular}

Control, and Mueller

\begin{tabular}{|c|c|c|c|c|c|c|c|c|c|c|c|c|c|c|}
\hline \multicolumn{15}{|c|}{ Phase II } \\
\hline \multicolumn{3}{|c|}{ Control } & \multicolumn{12}{|c|}{ After Mueller } \\
\hline \multirow[b]{2}{*}{$\dot{Q} c$} & \multirow[b]{2}{*}{ HR } & \multirow[b]{2}{*}{ sv } & \multicolumn{6}{|c|}{ Phase II A } & \multicolumn{6}{|c|}{ Phase II B } \\
\hline & & & $\dot{Q} \mathbf{c}$ & $\Delta \dot{Q} \mathrm{c}$ & HR & $\Delta \mathrm{HR}$ & SV & $\Delta \mathrm{SV}$ & $\dot{Q}_{c}$ & $\Delta \dot{Q} \mathrm{c}$ & HR & $\Delta \mathrm{HR}$ & sv & $\Delta \mathrm{SV}$ \\
\hline 3.4 & 82 & 41 & 3.4 & 0 & 88 & +6 & 38 & -3 & & & & & & \\
\hline 3.3 & 68 & 49 & 3.0 & -0.3 & 69 & +1 & 44 & -5 & 2.9 & -0.4 & 62 & -6 & 47 & -2 \\
\hline 3.0 & 66 & 45 & 2.2 & -0.8 & 55 & -11 & 41 & -4 & 2.3 & -0.7 & 52 & -14 & 43 & -2 \\
\hline 3.2 & 74 & 43 & 3.8 & +0.6 & 87 & +13 & 44 & +1 & 3.9 & +0.7 & 94 & +20 & 42 & -1 \\
\hline 3.23 & 72.5 & 44.5 & 3.10 & -0.13 & 74.8 & +2.3 & 41.8 & -2.8 & 3.03 & -0.13 & 69.3 & 0.0 & 44.0 & -1.7 \\
\hline \multirow{2}{*}{0.17} & 7.2 & 3.4 & 0.68 & 0.5 & 15.8 & 10.1 & 2.9 & 2.8 & 0.81 & 0.8 & 21.9 & 18 & 2.6 & 0.9 \\
\hline & & & & NS & & NS & & NS & & NS & & NS & & NS \\
\hline
\end{tabular}

during and after a Mueller. Table II A and B show values obtained following exercise. Mean values are summarized in Fig. 6. Only significant values $(P<0.05)$ will be mentioned in this section.

At rest, during a Valsalva maneuver (mean mouth pressure 24, SD $3.0, \mathrm{~mm} \mathrm{Hg}$ ), Q்c decreased from a control value of 2.58 , SD 0.43 , liters $/ \mathrm{min}$ per $\mathrm{m}^{2}$ to 1.62 , SD 0.26 , liters/min per $\mathrm{m}^{2}$. Stroke volume decreased during the strain from a control of 42.4 , sD $8.8, \mathrm{ml} /$ beat per $\mathrm{m}^{2}$ to 25.2 , sD $5.5, \mathrm{ml} /$ beat per $\mathrm{m}^{2}$. After the Valsalva, Q̀c overshot by 0.78 , sD 0.41 , liters $/ \mathrm{min}$ per $\mathrm{m}^{2}$, above the control in phase II A and then fell to 0.26 , SD 0.15 , liters $/ \mathrm{min}$ per $\mathrm{m}^{2}$ above the control in phase II B. This overshoot was associated with a significant increase in the heart rate over the controls $(+15.2$, SD 9.7 , beats $/ \mathrm{min}$ in phase II A and +4.6, SD 1.3, beats/min in phase II B). Changes in Q $c$, heart rate, and stroke volume during and after the Mueller maneuver at rest and exercise were not significant. Effects of a Valsalva maneuver sustained for $10 \mathrm{sec}$ by one subject (H.A.M.) are shown in Fig. 7. Q́c and stroke volume decreased steadily during the maneuver.

During simple breathholding with air, at rest under water, the average rate of decrease in lung volume $\left(\dot{\mathrm{V}}_{2}-\dot{\mathrm{V}} \mathrm{CO}_{2}\right)$ was 182 , SD $80, \mathrm{ml} \mathrm{BTPS} / \mathrm{min}$. It was 416, sD $100, \mathrm{ml} \mathrm{BTPS} / \mathrm{min}$ while the subjects held their breath after $2 \mathrm{~min}$ of exercise.

For one subject (Fig. 8), the records of gas exchange during breath-holding were analyzed in $2-\mathrm{sec}$ intervals so that transient changes could be detected. Q́c decreased gradually during simple breathholding at rest. $\dot{\mathrm{V}} \mathrm{O}_{2}$ and $\dot{\mathrm{V}} \mathrm{CO}_{2}$ also decreased but the rate of decrease of $\dot{\mathrm{V}} \mathrm{CO}_{2}$ was greater than that of $\dot{\mathrm{V}}_{2}$. During the Valsalva maneuver, Q́c was lower than during simple breathholding, and after release of the Valsalva there was an overshoot in $\dot{Q}$ c. It reached a peak at about $3 \mathrm{sec}$ after the release of the positive pressure, then fell rapidly. $\dot{\mathrm{VO}}_{2}$ followed a similar pattern. During the Mueller maneuver, Q́c decreased rapidly in this subject, but it returned to the initial value after release. $\dot{\mathrm{Vo}}_{2}$ 


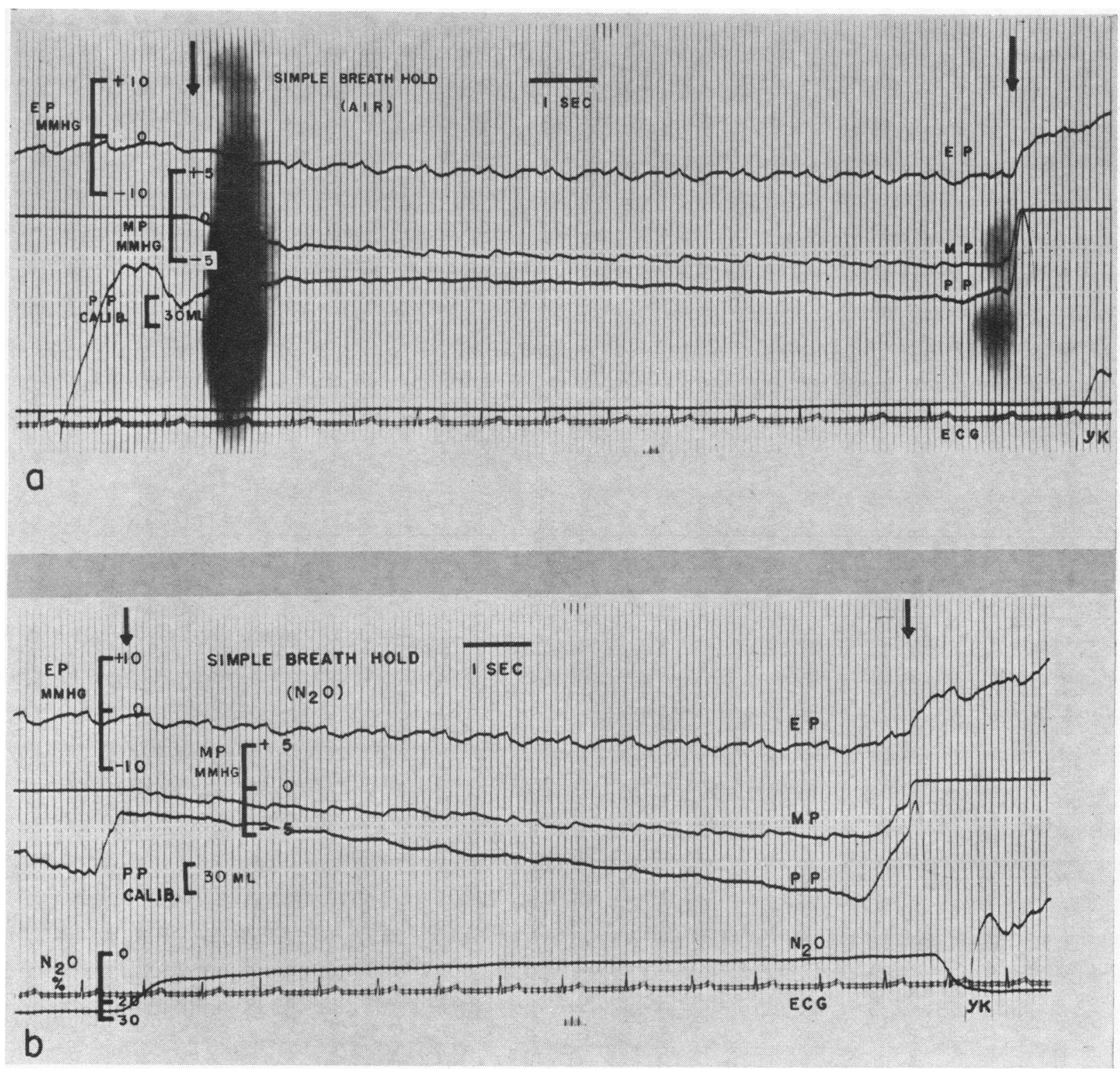

FIGURE 3 Simultaneous recordings of plethysmograph pressure, mouth pressure, $\mathrm{N}_{2} \mathrm{O}$ concentration, and ECG during simple breath holding. (a) breath holding on air. (b) breath holding on $\mathrm{N}_{2} \mathrm{O}$. The subject (Y. K.) had an esophageal balloon. EP, esophageal pressure; MP, mouth pressure; PP plethysmograph pressure. Arrows at the top of the record show the onset and termination of breath holding.

followed a similar pattern, but $\dot{\mathrm{V}} \mathrm{CO}_{2}$ decreased rapidly irrespective of changes in $\dot{Q} \mathrm{c}$.

After moderate exercise (Fig. $8 \mathrm{~B}$ ) values for $\dot{\mathrm{Q}} \mathrm{c}$, $\dot{\mathrm{V}} \mathrm{O}_{2}$, and $\dot{\mathrm{V}} \mathrm{CO}_{2}$ were higher than those at rest. Patterns of $\dot{Q} c$ and $\dot{V}_{2}$ during and after the Valsalva maneuver after exercise were similar to those with the Valsalva at rest. $\dot{\mathrm{V}} \mathrm{CO}_{2}$, however, showed an overshoot following the release of the Valsalva.

\section{DISCUSSION}

The objectives of this experiment were $(a)$ to design, build, and test a water-filled hody plethysmograph; (b) to determine whether it would be useful for studying changes in respiration of a person under water; and (c) to determine whether it would make possible special measurements which could not be carried out with an air-filled plethysmograph. Although special training 


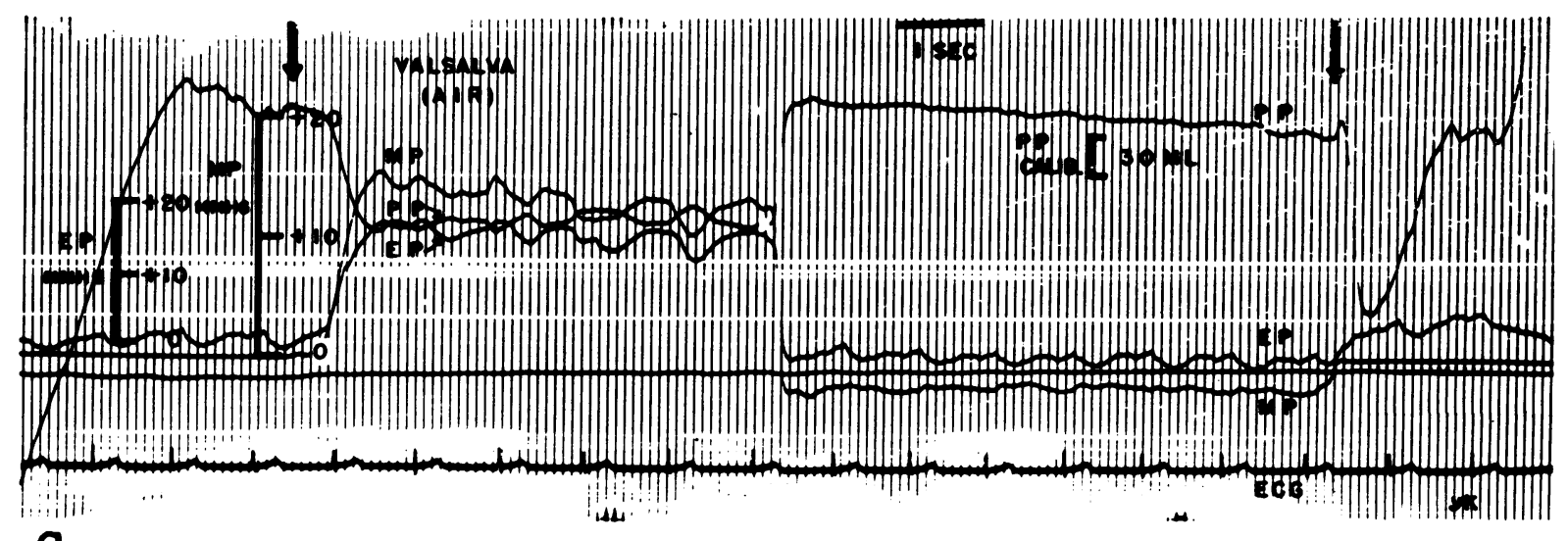

a

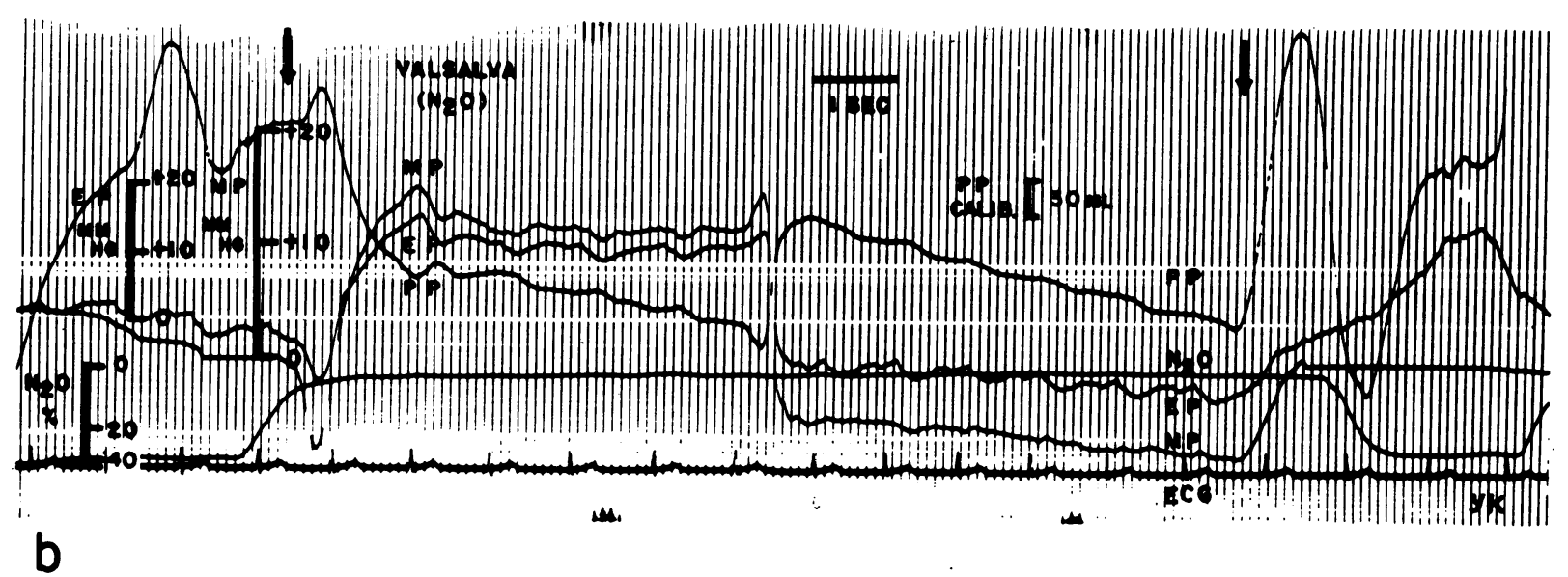

FIGURE 4 Simultaneous recordings of plethysmograph pressure, mouth pressure, $\mathrm{N}_{2} \mathrm{O}$ concentration, and ECG during and after a Valsalva maneuver. (a) Control after inspiring air. (b) After inspiring $\mathrm{N}_{2} \mathrm{O}$. For abbreviations see legend to Fig. 3.

was necessary before the subjects could be tested, it was found that they adapted readily to the plethysmograph and were able to perform breath-holding maneuvers during their first session in the plethysmograph. The factor which limited the sensitivity or signal to noise ratio was the noise level of about $0.2 \mathrm{ml}$ resulting from floor vibrations.

Effects of water immersion. In our subjects, total water immersion decreased the respiratory frequency significantly. It was unlikely that the temperature of the water $\left(35^{\circ} \mathrm{C}\right)$ caused this, since warm water (between $30^{\circ}$ and $40^{\circ} \mathrm{C}$ ) does not decrease frequency of breathing (10), although cold showers increase it. On the other hand, the standpipe and breathing tubes of the plethysmograph added resistance to breathing, which would have caused a slower frequency.

Craig reported that oxygen consumption did not change significantly from the basal state after immersing the body up to the neck in $35^{\circ} \mathrm{C}$ water (4). We also found this. In addition, we found no significant change in $\mathrm{CO}_{2}$ output. However, there was a significant decrease of the respiratory exchange ratio. One of the possible explanations for this decrease was that hyperventilation preceded the measurements, resulting in lowered body stores of $\mathrm{CO}_{2}$. In the studies of Keatinge and Evans (11), minute volume of ventilation rose slightly after immersion in $35^{\circ} \mathrm{C}$ water (up to the neck), but returned to normal after a couple of minutes. In our study, the measurement of $\mathrm{CO}_{2}$ output was done after at least $20 \mathrm{~min}$ of immersion. However, it was not known whether $\mathrm{CO}_{2}$ stores were normal at the time of the measurements.

In our subjects, immersion did not change the heart rate, measured during simple breathholding. In that respect, whole body immersion was similar to face immersion in warm or cool $\left(30^{\circ}-37^{\circ} \mathrm{C}\right)$ water (12). 

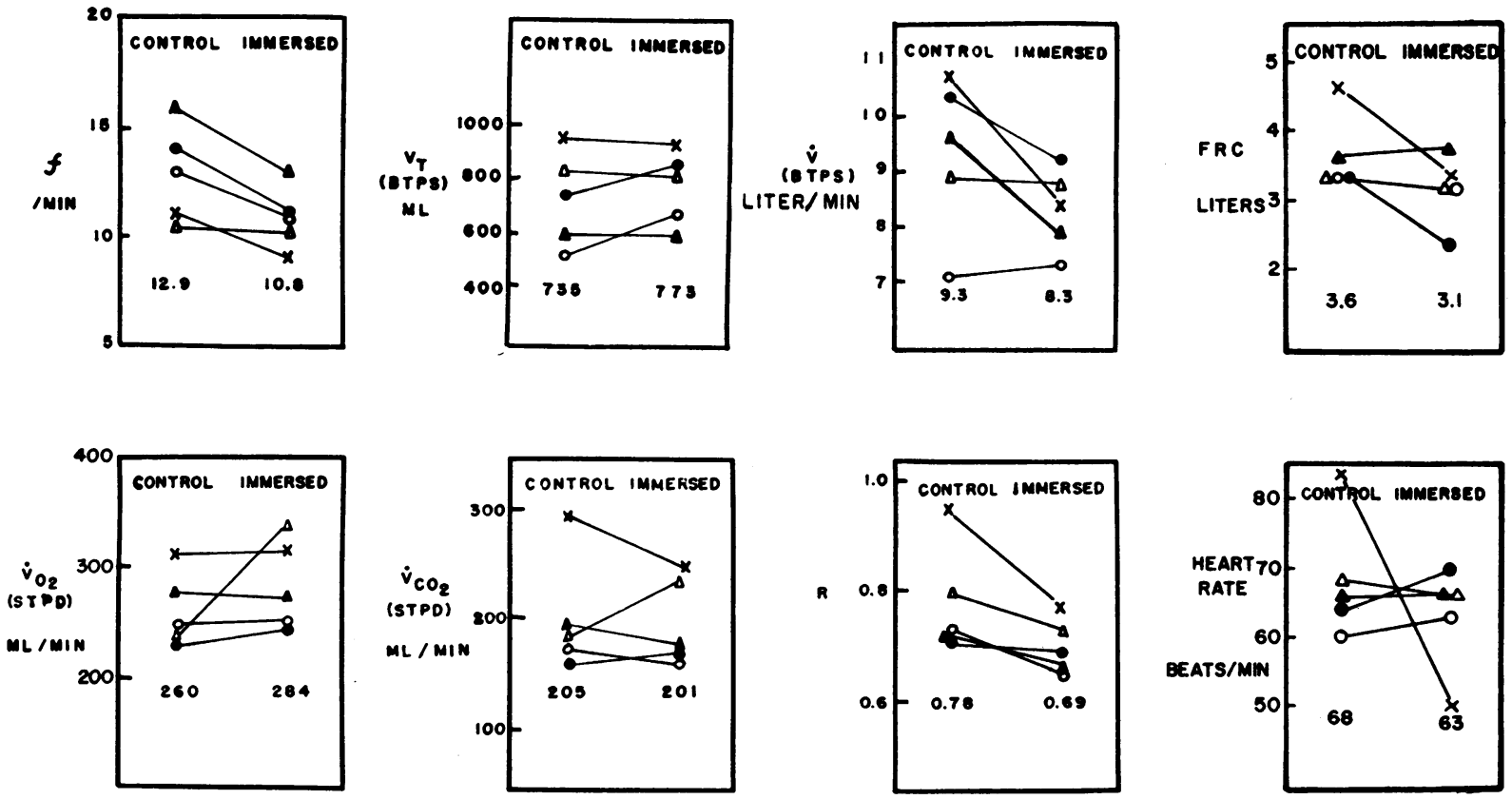

FIGURE 5 Effects of total immersion on respiratory frequency ( $f$ ), tidal volume $\left(V_{T}\right)$, minute volume $(\dot{\mathrm{V}}), \mathrm{O}_{2}$ consumption $\left(\dot{\mathrm{V}}_{2}\right), \mathrm{CO}_{2}$ output $\left(\dot{\mathrm{V}} \mathrm{CO}_{2}\right)$, respiratory gas exchange ratio (R), functional residual capacity (FRC), and heart rate. Numbers at the bottom of each column are mean values.

The hemodynamics in our subjects sitting in water might be compared to those in the supine or weightless subject since the effect of gravity was largely abolished, except within the thorax.

FRC in our subjects did not change significantly when they were immersed. Agostoni, Curtner, Torri, and Rahn reported a $46 \%$ decrease in FRC during immersion up to the neck (13). Since atmospheric pressure was at the level of our subject's shoulders, we might have expected a similar decrease. However, the relative negative pressure above our subject's shoulders as well as the vital capacity maneuver which they performed before breath-holding may have prevented a decrease.

Effects of intrathoracic pressure changes on pulmonary capillary blood flow. The effects of a Valsalva on systemic hemodynamics have been studied extensively. Booth, Mellette, Swiss, and Ryan (1) reported that vasoconstriction and increased systemic blood pressure appeared after $5 \mathrm{sec}$ of a Valsalva, and that after the release of the Valsalva an overshoot in systemic blood pressure occurred. In a report of underwater measurements Craig (14) showed no overshoot of systemic blood pressure after a Valsalva.

On the other hand, pulmonary circulation has been less accessible to study during a Valsalva. Lee, Matthews, and Sharpey-Shafer (15) found that "net" pulmonary arterial wedge pressure (arterial pressure minus intraesophageal pressure) fell during a Valsalva and, after release, returned suddenly to control levels then gradually rose above the control (overshoot). Tachycardia occurred shortly after the release, and a bradycardia accompanied the overshoot. We found a diminished Q̀c during a $5 \mathrm{sec}$ Valsalva maneuver and an overshoot in heart rate and $\dot{Q} c$ after the release. Though the duration of the Valsalva maneuver was relatively short $(5 \mathrm{sec})$ one subject sustained it for $10 \mathrm{sec}$, and the bloodflow remained low during the entire $10 \mathrm{sec}$ period of straining. The overshoot in our subjects was accompanied by a tachycardia. Although the overshoot of $\dot{Q} c$ which we found might be associated with an overshoot in pulmonary wedge pressure such as found by Lee et al., it appears that their subjects exhaled after the maneuver, whereas ours continued to hold their breath. Thus the rebound phenomenon in their subjects was the result of changes both in lung volume and intrathoracic pressure, whereas the rebound phenomenon in our subjects was without much change of lung volume.

Ross, Linhart, and Braunwald (16) showed that stroke volume could increase after exercise with a heart rate held constant (over 90 beats per min) by electrical stimulation. They concluded that even when changes in heart rate were absent cardiac output could rise because of an increase in stroke volume in muscular exercise. We found that right ventricular stroke volume 


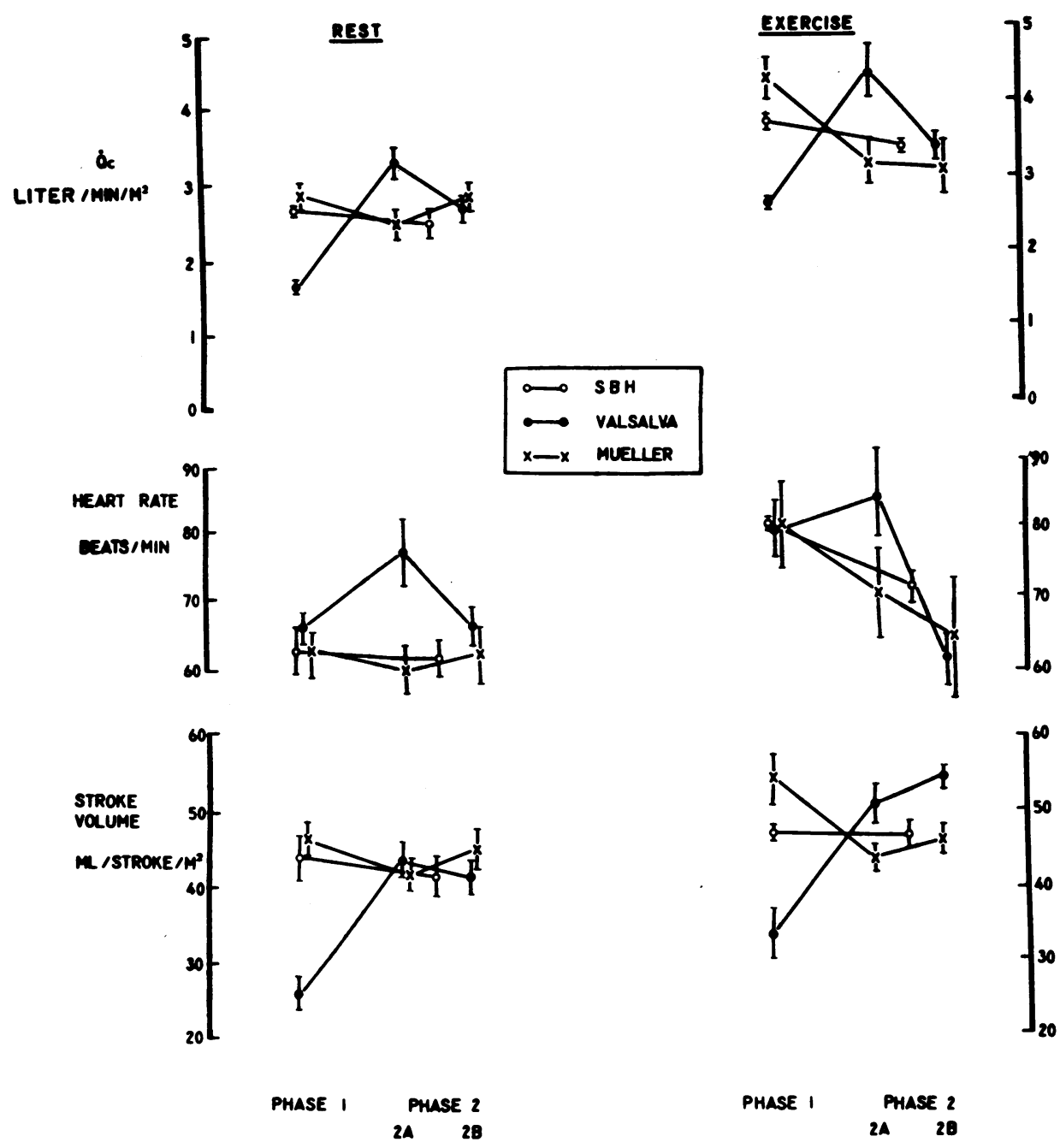

FIGURE 6 Mean values for Qc, heart rate, and stroke volume at rest and after exercise. Bars indicate one standard error from the mean. Q́c: pulmonary capillary blood flow. Each point in the figure represents $\dot{Q} c$ from two to three cardiac cycles.

could decrease independently of heart rate during the 5 sec Valsalva maneuver during rest or after exercise. This decrease in stroke volume was observed when the heart rate was below 80 beats per min.

Increases in $\dot{Q} c$ after exercise $(38 \%)$ in our present study are comparable to those $(31 \%)$ seen in a horizontal body plethysmograph after a similar amount of exercise (17).

DuBois and Marshall showed that $\dot{Q} c$ did not vary appreciably during the normal respiratory cycle in man (18). However, an increase in Q́c associated with cardiac acceleration has been observed toward the end of a slow inspiration, and a decrease associated with cardiac deceleration toward the end of a slow expiration $(18,19)$. From these observations, one might expect the Q $c$ would increase during the Mueller maneuver. However we did not find a significant increase in $\dot{Q} c$ during the Mueller either at rest or after exercise. Vermeire and Butler (19) reported that in the sitting position the increase pulmonary capillary blood flow at the start of inspiration, when the esophageal pressure was about $-4 \mathrm{~mm} \mathrm{Hg}$, was not increased when the esophageal pressure was lowered further. Guyton, Lindsay, Abernathy, and Richardson (20) showed, in open-chest dogs, that venous return reached a maximum value when the right atrial pressure fell to -2 to -4 $\mathrm{mm} \mathrm{Hg}$. It remained at this maximum value at lower pressures as systemic veins progressively collapsed. That is, a waterfall effect was produced so that ambient pressure rather than right atrial pressure limited venous 


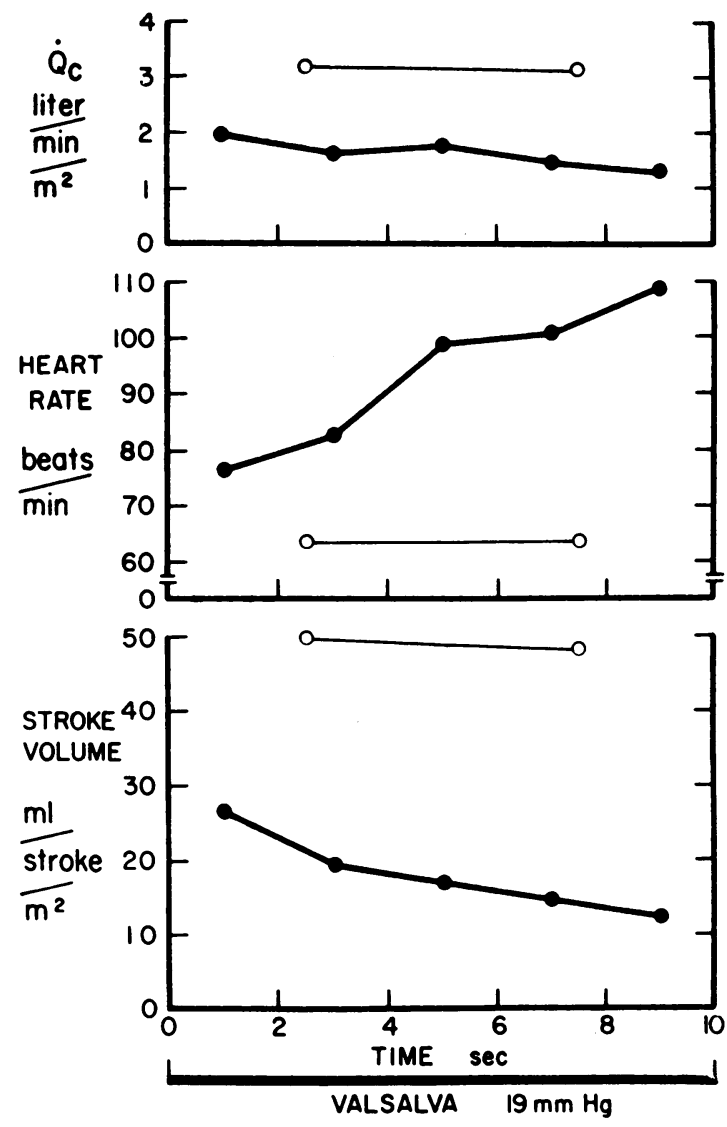

FIGURE 7 Effects of a prolonged Valsalva maneuver on $\dot{Q} c$, heart rate, and stroke volume (closed circles). Each point represents flow during two to three cardiac cycles. Mean values from two measurements in subject $H$. A. M. are shown. Control values of $\dot{Q} c$, heart rate, and stroke volume (open circles) obtained during simple breath holding are also shown.

return. Craig (14) has shown that peripheral venous pressure increases under water, a finding we might have expected in our plethysmograph. However, since we did not find significant changes in Q̣c during the Mueller at rest or after exercise, we concluded that peripheral venous pressure did not rise enough in relation to ambient pressure to affect venous return.

Effects of intrathoracic pressure changes on gas exchange in the lungs. The rate of absorption of oxygen from the alveolar air into the pulmonary blood, and output of $\mathrm{CO}_{2}$ from the blood into the alveolar gas, seemed to depend on two factors; the first was the rate of bloodflow, and the second was the arterio-venous content difference. The changes in bloodflow during Valsalva and Mueller procedures were described above. The alterations in arterio-venous content difference will be described below.

The venous content of oxygen or carbon dioxide remained relatively constant throughout breath-holding provided the period of breathholding did not exceed a single circulation time. However, the arterial oxygen or carbon dioxide content was not necessarily constant, but depended on the partial pressure of the gas in the alveoli, and this changed with the alveolar pressure. During simple breathholding, the alveolar $\mathrm{Po}_{2}$ decreased with time, but not enough to cause much desaturation of the arterial blood. Similarly, a Valsalva or Mueller maneuver changed the alveolar $\mathrm{Po}_{2}$ but not so much as to appreciably supersaturate or desaturate the arterial blood. Thus, the rate of oxygen uptake, while dependent on the rate of bloodflow, was relatively independent of alveolar pressure, except insofar as the latter affected bloodflow. The rate of carbon dioxide output, on the other hand, was less dependent upon bloodflow, because the alveolar $\mathrm{PCO}_{2}$ almost reached venous tension early in breath holding (21), and therefore the arteriovenous content difference was small. However, if the alveolar $\mathrm{PCO}_{2}$ was altered by straining, the arterial $\mathrm{CO}_{2}$ content was affected, and hence the rate of $\mathrm{CO}_{2}$ uptake was affected. Therefore, $\mathrm{CO}_{2}$ output, though insensitive to changes in bloodflow, was quite sensitive to mechanically induced changes of partial pressure in the lungs. Table III shows changes in partial pressure gradients for $\mathrm{O}_{2}$ and $\mathrm{CO}_{2}$ in subject $\mathrm{H}$. A. M. calculated for different intrathoracic pressures. The effects of these

TABLE III

\begin{tabular}{|c|c|c|c|c|c|c|c|c|c|c|c|}
\hline & \multicolumn{2}{|c|}{ Total gas pressure } & \multicolumn{2}{|c|}{$\mathrm{Po}_{2}$} & \multicolumn{2}{|c|}{$\mathrm{PcO}_{2}$} & \multicolumn{2}{|c|}{$\begin{array}{l}\text { Pressure } \\
\text { gradient }\end{array}$} & \multicolumn{2}{|c|}{$\begin{array}{l}\text { Calculated effect of } \\
\text { change in pressure } \\
\text { gradient }\end{array}$} & \multirow{2}{*}{$\begin{array}{l}\text { Observed } \\
\text { change } \\
\text { in Q்c }\end{array}$} \\
\hline . & Alveolar & $\begin{array}{l}\text { Mixed } \\
\text { venous }\end{array}$ & Alveolar & $\begin{array}{l}\text { Mixed } \\
\text { venous }\end{array}$ & Alveolar & $\begin{array}{r}\text { Mixed } \\
\text { venous }\end{array}$ & $\mathrm{O}_{2}$ & $\mathrm{CO}_{2}$ & $\mathrm{O}_{2}$ & $\mathrm{CO}_{2}$ & \\
\hline & \multicolumn{2}{|c|}{$m m \mathbf{H g}$} & \multicolumn{2}{|c|}{$m m \mathrm{Hg}$} & \multicolumn{2}{|c|}{$m m \mathrm{Hg}$} & \multicolumn{2}{|c|}{$m m \mathrm{Hg}$} & \multicolumn{2}{|c|}{$\%$} & $\%$ \\
\hline holding & $760-47$ & $706-47$ & 100 & 40 & 40 & 46 & 60 & 6 & & & \\
\hline Valsalva & $760-47+26$ & $706-47$ & 103.5 & 40 & 41.4 & 46 & 63.5 & 4.6 & +1.4 & -20.0 & -31.9 \\
\hline Mueller & $760-47-29$ & $706-47$ & 95.8 & 40 & 38.3 & 46 & 55.8 & 7.7 & -2.8 & +22.5 & +8.6 \\
\hline
\end{tabular}

Calculations of partial pressure gradient for $\mathrm{O}_{2}$ and $\mathrm{CO}_{2}$ during changes in alveolar pressure (subject $\mathrm{H}$. A. M.). Total gas pressure in the mixed venous blood was assumed to be $706 \mathrm{~mm} \mathrm{Hg}$. Mouth pressures were +26 and $-29 \mathrm{~mm} \mathrm{Hg}$ for Valsalva and Mueller maneuvers, respectively. 

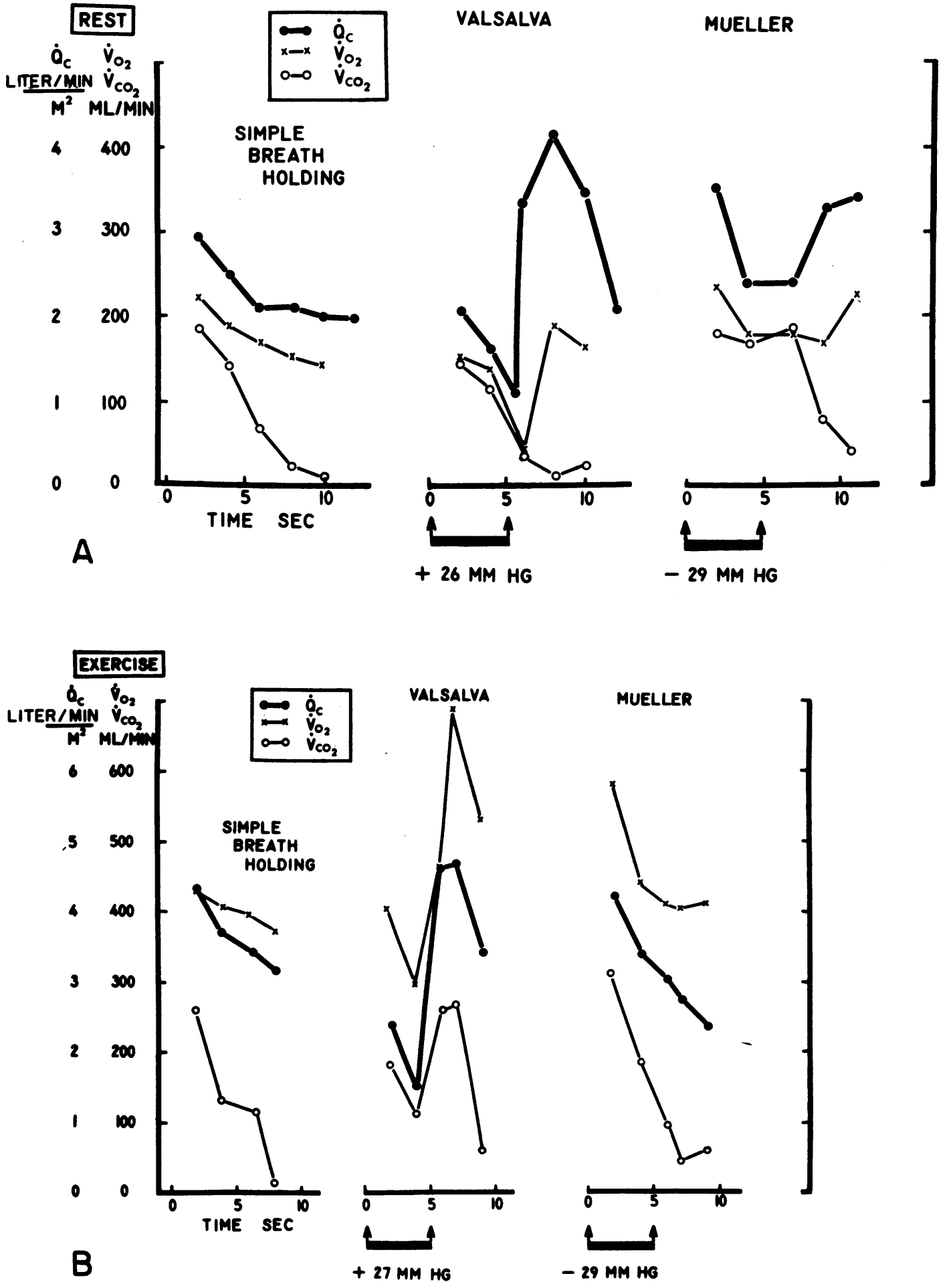

FIgUre 8 Time course of the changes in $\dot{Q} c, \dot{V}_{2}$, and $\dot{V} c_{J_{2}}$ duri.g breath holding. A. At rest. B. After exercise. (Subject H. A. M.). Each point represents mean values from two to three measurements. 
changes on gas exchange were calculated using the appropriate dissociation curve for each gas. Measurements of $\dot{Q} c$ during a Valsalva or Mueller are shown in the same table. It can be seen from Table III and referring to Fig. 8 that changes in $\dot{\mathrm{V}}_{2}$ primarily reflected changes in $\dot{Q} c$ whereas changes in $\dot{\mathrm{V}} \mathrm{CO}_{2}$ depended primarily on the partial pressure gradient between alveoli and blood. Therefore, $\dot{\mathrm{V}} \mathrm{CO}_{2}$ became relatively independent of $\dot{Q} c$ during breath holding except perhaps after exercise. In that case, the $\mathrm{PCO}_{2}$ gradient between alveoli and blood might have been high enough during phase II to explain the positive overshoot in $\dot{\mathrm{V}} \mathrm{CO}_{2}$ which occurred as a result of the overshoot in $\dot{Q} c$.

\section{APPENDIX}

When the plethysmograph is closed with no subject inside it,

where:

$$
\frac{\Delta \mathrm{V}_{\mathrm{P}}}{\Delta \mathrm{P}_{\mathbf{p}}}=K
$$

$\Delta \mathrm{V}_{\mathrm{P}}=$ change in volume of the contents of the plethysmograph

$\Delta \mathrm{P}_{\mathrm{p}}=$ change in pressure within the plethysmograph, and $K=$ calibrating factor.

In practice, $K$ was obtained by injecting a known volume of water into the plethysmograph which was filled with water.

When a subject holds his breath in the plethysmograph,

$$
\Delta \mathrm{V}_{\mathrm{L}}=\Delta \mathrm{V}_{\mathrm{p}}
$$

where:

$\Delta \mathrm{V}_{\mathrm{L}}=$ change in volume of lung gas.

Assuming that lung volume depends only on alveolar pressure and gas exchange then,

$$
\Delta \mathrm{V}_{\mathrm{L}}=\Delta \mathrm{V}_{\mathrm{L}}^{\mathrm{c}}+\Delta \mathrm{V}_{\mathrm{L}}^{\mathrm{GA}}
$$

where:

$$
\begin{aligned}
\Delta \mathrm{V}_{\mathrm{L}} \mathrm{C}= & \begin{array}{l}
\text { change in volume of lung gas because of com- } \\
\text { pression or decompression, and }
\end{array} \\
\Delta \mathrm{V}_{\mathrm{L}} \mathrm{GA}= & \text { change in volume of lung gas because of gas }
\end{aligned}
$$
absorption or evolution.

If at some time during the breath holding procedure, the subject voluntarily changes his intrathoracic pressure rapidly, one can use Boyle's Law to show that:

$$
\frac{K \cdot \Delta \mathrm{P}_{\mathrm{p}} \mathrm{v}}{\Delta \mathrm{P}_{\mathrm{L}} \mathrm{v}}=\frac{\mathrm{V}_{\mathrm{L}}}{\mathrm{B}-47}
$$

where:

$$
\begin{aligned}
K \cdot \Delta \mathrm{P}_{\mathrm{p}} \mathrm{v}= & \text { Change in volume of lung gas during this rapid } \\
& \text { maneuver } \\
\Delta \mathrm{P}_{\mathrm{L}} \mathrm{v}= & \text { change in intrathoracic pressure during this } \\
\text { rapid maneuver } & \\
\mathrm{V}_{\mathrm{L}}= & \text { volume of lung gas (assumed to be nearly } \\
& \text { constant throughout breath holding in these } \\
& \text { calculations), and } \\
\mathrm{B}-47= & \text { barometric pressure - pressure of water vapor } \\
& \text { at } 37^{\circ} \mathrm{C} .
\end{aligned}
$$

By Boyle's Law, during the breath holding procedure,

$$
\Delta \mathrm{V}_{\mathrm{L}} \mathrm{c}=\Delta \mathrm{P}_{\mathrm{L}} \cdot \frac{\mathrm{V}_{\mathrm{L}}}{\mathrm{B}-47}
$$

where:

$\Delta \mathrm{P}_{\mathrm{L}}=$ change in intrathoracic gas pressure.

Substituting equation 4 into equation 5

$$
\Delta \mathrm{V}_{\mathrm{L}}^{\mathrm{c}}=\Delta \mathrm{P}_{\mathrm{L}} \cdot \frac{K \cdot \Delta \mathrm{P}_{\mathrm{P}} \mathrm{v}}{\Delta \mathrm{P}_{\mathrm{L}} \mathrm{v}}
$$

Substituting equations 6,2 , and 1 , into equation 3 , and rearranging the terms,

where:

$$
\Delta \mathrm{V}_{\mathrm{L}}^{\mathrm{GA}}=K\left(\mathrm{P}_{\mathrm{p}}-\frac{\Delta \mathrm{P}_{\mathrm{P}}^{\mathrm{v}}}{\Delta \mathrm{P}_{\mathrm{L}}^{\mathrm{v}}} \cdot \Delta \mathrm{P}_{\mathrm{L}}\right)
$$

$\Delta \mathrm{P}_{\mathrm{P}}=$ change in plethysmograph pressure.

This equation is used in calculating gas absorption during breath holding in the plethysmograph.

\section{ACKNOWLEDGMENT}

This work was supported in part by Grant HE-4797 from the U. S. Public Health Service.

\section{REFERENCES}

1. Booth, R. W., H. Mellette, E. Swiss, and J. M. Ryan. 1960. The hemodynamics of the Valsalva maneuver in normal subjects. Clin. Res. $8: 178$. (Abstr.)

2. Daly, J. J., M. Calabresi, R. G. Nims, and F. D. Gray, Jr. 1960. The effect of the Valsalva maneuver on pulmonary hemodynamics in emphysema. Clin. Res. 8: 254. (Abstr.)

3. Wolkowski, J. J., K. Paulsen, and A. C. De Graff, Jr. 1968. Pulmonary flow (Qc) and diffusing capacity (DLCO) during Valsalva. Fed. Proc. 27 : 379. (Abstr.)

4. Craig, A. B., Jr., and M. Dvorak. 1966. Thermal regulation during water immersion. J. Appl. Physiol. 21: 1577.

5. DuBois, A. B., S. Y. Botelho, G. N. Bedell, R. Marshall, and J. H. Comroe, Jr. 1956. A rapid plethysmographic method for measuring thoracic gas volume: a comparison with a nitrogen washout method for measuring functional residual capacity in normal subjects. J. Clin. Invest. 35: 322.

6. Lee, G. de J., and A. B. DuBois. 1955. Pulmonary capillary blood flow in man. J. Clin. Invest. 34: 1380.

7. Kety, S. S., M. H. Harmel, H. T. Broomell, and C. B. Rhode. 1948. The solubility of nitrous oxide in blood and brain. J. Biol. Chem. 173: 487.

8. Wasserman, K., and J. H. Comroe, Jr. 1962. A method for estimating instantaneous pulmonary capillary blood flow in man. J. Clin. Invest. 41: 401.

9. Sackner, M. A., K. A. Feisal, and A. B. DuBois. 1964. Determination of tissue volume and carbon dioxide dissociation slope of the lungs in man. J. Appl. Physiol. $19: 374$.

10. Keatinge, W. R., and J. A. Nadel. 1965. Immediate respiratory response to sudden cooling of the skin. $J$. Appl. Physiol. 20 : 65.

11. Keatinge, W. R., and M. Evans. 1961. The respiratory and cardiovascular response to immersion in cold and warm water. Quart. J. Exp. Physiol. 46: 83.

12. Kawakami, Y., B. H. Natelson, and A. B. DuBois. 1967. Cardiovascular effects of face immersion and factors affecting diving reflex in man. J. Appl. Physiol. 23: 964. 
13. Agostoni, E., G. Gurtner, G. Torri, and H. Rahn. 1966. Respiratory mechanics during submersion and negativepressure breathing. J. Appl. Physiol. $21: 251$.

14. Craig, A. B., Jr. 1965. Effects of submersion and pulmonary mechanics on cardiovascular function in man. In Physiology of Breath Hold Diving and the Ama of Japan. H. Rahn, editor. NAS-NRC Washington, D. C. 295.

15. Lee, G. de J., M. B. Matthews, and E. D. Sharpey-Shafer. 1954. The effect of the Valsalva manoeuvre on the systemic and pulmonary arterial pressure in man. Brit. Heart $J$. $16: 311$.

16. Ross, J., Jr., J. W. Linhart, and E. Braunwald. 1965. Effects of changing heart rate in man by electrical stimulation of the right atrium. Circulation. 32 : 549.
17. Miyamoto, Y., Y. Kawakami, and M. Mochizuki. 1965. Pulmonary capillary blood flow in man measured by a new $\mathrm{N}_{2} \mathrm{O}$ analyzer. Jap. J. Physiol. 15: 505.

18. DuBois, A. B., and R. Marshall. 1957. Measurements of pulmonary capillary blood flow and gas exchange throughout the respiratory cycle in man. J. Clin. Invest. 36: 1566.

19. Vermeire, P., and J. Butler. 1968. Effect of respiration on pulmonary capillary blood flow in man. Circ. Res. 22: 299.

20. Guyton, A. C., A. W. Lindsey, B. Abernathy, and T. Richardson. 1957. Venous return at various right atrial pressures and the normal venous return curve. Amer. J. Physiol. 189 : 609.

21. DuBois, A. B. 1952. Alveolar $\mathrm{CO}_{2}$ and $\mathrm{O}_{2}$ during breath holding, expiration, and inspiration. J. Appl. Physiol. 5:1 